\title{
Differential and Region-Specific Activation of Mitogen-Activated Protein Kinases Following Chronic Administration of Phencyclidine in Rat Brain
}

Svetlana V. Kyosseva, Ph.D., S. Michael Owens, Ph.D., Alan D. Elbein, Ph.D., and Craig N. Karson, M.D.

We have previously demonstrated elevation of the extracellular signal-regulated kinase (ERK) pathway in the cerebellum from patients with schizophrenia, an illness that may involve dysfunction of the N-methyl-D-aspartate (NMDA) receptor. Since the NMDA antagonist, phencyclidine $(P C P)$, produces schizophrenic-like symptoms in humans, and abnormal behavior in animals, we examined the effects of chronic PCP administration in time- and dose-dependent manner on ERK and two other members of mitogen-activated protein kinase family, c-Jun $N$-terminal protein kinase (JNK) and $p 38$, in rat brain. Osmotic pumps for PCP $(18 \mathrm{mg} / \mathrm{kg} /$ day $)$ and saline (controls) were implanted subcutaneously in rats for three, 10, and 20 days. Using Western blot analysis, we found no change at three days, but a significant increase in the phosphorylation of ERK1, ERK2 and MEK in the cerebellum at 10- and 20-days of continuous PCP infusion. For the experiments involving various doses of $P C P$, rats were infused with PCP at concentrations of 2.5, 10, 18, or $25 \mathrm{mg} / \mathrm{kg} /$ day, or saline for 10 days. We observed a dosedependent elevation in the phosphorylation of ERK1 and ERK2 only in the cerebellum but not in brainstem, frontal cortex or hippocampus. The activities of JNK and p38 were unchanged in all investigated brain regions including cerebellum. These results demonstrate that chronic infusion of $P C P$ in rats produces a differential and brain regionspecific activation of MAP kinases, suggesting a role for the ERK signaling pathway in PCP abuse and perhaps in schizophrenia.

[Neuropsychopharmacology 24:267-277, 2001]

(C) 2001 American College of Neuropsychopharmacology.

Published by Elsevier Science Inc.
KEY WORDS: Phencyclidine; Rat cerebellum; Signal transduction; ERK; JNK; p38 MAP kinase

Phencyclidine (PCP) is a hallucinogenic drug, which in normal humans can produce psychotic reactions that

From the Departments of Biochemistry and Molecular Biology (SVK, ADE), Psychiatry (SVK), and Pharmacology and Toxicology (SMO), University of Arkansas for Medical Sciences, Little Rock, AR; and VA Boston Healthcare System, Boston, MA (CNK).

Address correspondence to: Dr. Svetlana V. Kyosseva, University of Arkansas for Medical Sciences, Department of Biochemistry and Molecular Biology, 4301 W. Markham Street, Little Rock, Arkansas 72205.

Received 30 March 2000; revised 14 July 2000; accepted 19 July 2000 . resemble positive, negative, and cognitive symptoms of schizophrenia (Javitt and Zukin 1991; Javitt et al. 1999). Because of these symptoms, it is suggested that PCP might be a useful drug-induced model of schizophrenia (Thornberg and Saklad 1996; Jentsch and Roth 1999; Sams-Dodd 1999).

In experimental animals, PCP produces dose-dependent increases in stereotyped behavior, locomotor activity, and ataxia. Although PCP affects multiple neurotransmitters, its main site of action is through binding to the so-called PCP receptor located within the ion channel formed by the N-methyl-D-aspartate (NMDA)type glutamate receptor (Javitt 1987; MacDonald et al. 1990; Javitt and Zukin 1991). PCP binding to this site in- 
hibits NMDA receptor functioning in a noncompetitive manner. There is also substantial evidence implicating NMDA dysfunction in the pathophysiology of schizophrenia and other psychiatric illnesses (Olney and Farber 1995; Coyle 1996; Krystal et al. 1999).

Several lines of evidence suggest an important role for the intracellular signal transduction pathways in the regulation of brain function, and mechanism of neural plasticity in responses to stress, antidepressant treatments and drugs of abuse (Duman et al. 1994, Duman 1998). One of these signal transduction pathways is the extracellular signal-regulated kinase (ERK) cascade, a member of the mitogen-activated protein (MAP) kinase family. This pathway converts extracellular stimuli at many cell surface receptors, such as tyrosine kinases and Gprotein coupled receptors (Marshall 1994; Crespo et al. 1994; Carraway and Carraway 1995), and ion channels associated with the NMDA-type glutamate receptors (Campos-Gonzalez and Kindy 1992; Gass et al. 1993; Kurino et al. 1995; Xia et al. 1996) to intracellular signals controlling gene expression (Guan 1994).

In the ERK pathway (Figure 1), Ras-GTP activates the serine/threonine kinase Raf, which in turn phosporylates and activates MEK1 and MEK2. Activated MEK, which is a dual specificity kinase, activates ERK1 and ERK2 (p44 and p42 MAP kinase) through phosphorylation on threonine and tyrosine residues. Activated ERKs are translocated to the nucleus and phosphorylate a variety of transcription factors including Elk-1, cAMP response element binding protein (CREB) and activating transcription factor (ATF). Both ERK 1 and ERK2 are highly expressed in neurons (Boulton and Cobb 1991; Thomas and Hunt 1993; English and Sweatt 1997; Flood et al. 1998). They can be activated in response to nerve growth factor (Boulton et al. 1991), electroconvulsive shock (Baraban et al. 1993; Kang et al. 1994; Bhat et al. 1998), and glutamate receptor stimulation (Bading and Greenberg 1991; Fiore et al. 1993a; Kawasaki et al. 1999). Moreover, recent studies have linked the MAP kinase cascade to important brain functions, such as memory consolidation and long-term neuronal plasticity (Berman et al. 1998; Blum et al. 1999; Impey et al. 1999). Two other classes of MAP kinases, c-Jun N-terminal kinase/stress-activated protein kinase (JNK/SAPK) and $\mathrm{p} 38$, are activated by various stress stimuli, including ultraviolet irradiation, inflammatory cytokines and osmotic shock (Han et al. 1994; Rouse et al. 1994; Freshney et al. 1994; Rosette and Karin 1996; Lewis et al. 1998).

In a previous study, we demonstrated increased levels of ERK2 protein in the cerebellar vermis but not in brainstem and frontal pole (Brodmann area 10) from patients with schizophrenia (Kyosseva et al. 1999). We found a significant elevation of MEK and c-Raf proteins in the vermis as well (unpublished results). Furthermore, we showed that the levels of downstream tran-

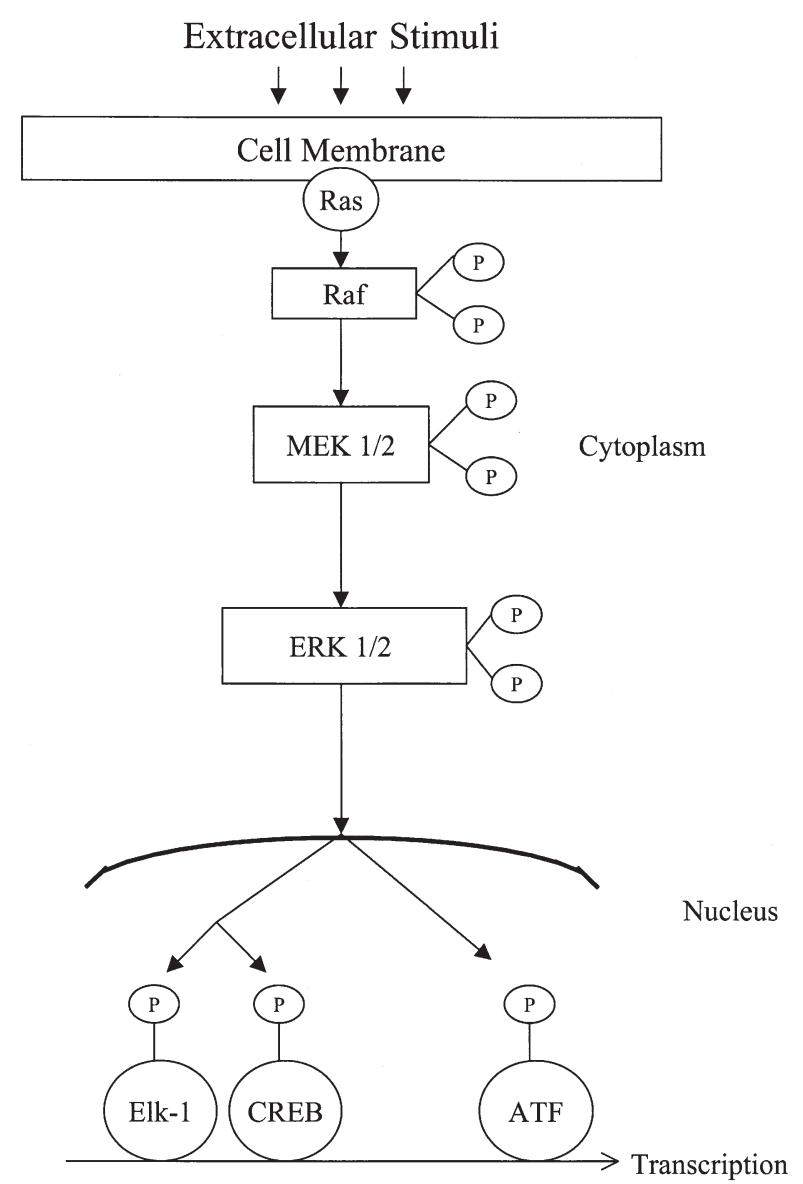

Figure 1. Schematic presentation of MAP kinase/ERK signaling cascade.

scription targets, such as Elk-1, CREB and ATF-2 were also elevated in the cerebellar vermis in patients with schizophrenia (Kyosseva et al. 2000).

In this study, we have, therefore, investigated whether chronic administration of PCP would produce alterations of MAP kinases in rat brain. Studies were conducted to determine the time- and dose-dependent effect of PCP on the activation of the MAP kinase cascades by measuring active forms of ERK and MEK, as well as JNK and p38 using Western blot analysis of brain tissue from rats infused with a pharmacologically active dose of PCP (Wessinger and Owens 1991).

\section{MATERIALS AND METHODS}

\section{Materials}

Phencyclidine hydrochloride was obtained from the National Institute on Drug Abuse (Rockville, MD). Osmotic pumps for subcutaneous implantation were supplied from ALZA Corp. (Palo Alto, CA). The pumps used were Models 2ML2 (capable of up to 14 days infusion). Leupeptin, aprotinin, pepstatin A, phenylmethyl- 
sulfonyl fluoride (PMSF), and sodium orthovanadate were purchased from Sigma Chemical Co. (St. Louis, $\mathrm{MO}$ ). The reagents for sodium dodecyl sulfate polyacrylamide gel electrophoresis (SDS-PAGE) and Western immunoblot analysis were obtained from Bio-Rad (Richmond, CA). Enhanced chemiluminescence (ECL) reagents were from Amersham (Arlington Heights, IL). Polyclonal phospho-specific p44/42 MAP kinase (corresponding to Thr 202 and Tyr 204 of human p44 MAP kinase), p44/42 MAP kinase (corresponding to residues 345 to 358 of rat p42 MAP kinase), phospho-MEK1/2 (corresponding to residues Ser 217/221 of human MEK1), MEK 1/2 (corresponding to residues 216 to 233 of human MEK1), phospho-JNK (residues Thr183/ Tyr185), JNK (full length p54 SAPK/JNK fusion protein), phospho-p38 MAP kinase (residues Thr180/ Tyr182), p38 MAP kinase (corresponding to residues 341 to 360 ) antibodies, and rabbit IgG-horseradish peroxidase conjugated antibody were purchased from New England Biolabs, Inc. (Beverly, MA). All other chemicals were of reagent grade or high purity and were obtained from Fisher Scientific (Springfield, NJ).

\section{Animals and PCP Dosing}

Adult male Sprague-Dawley rats (approximately $250 \mathrm{~g}$ ) were purchased from Harlan Sprague-Dawley, Inc. (Indianapolis, IN) and were allowed to acclimate to their new environment for one week before the experiments. Animal use procedures were in accordance with the National Institute of Health Guide for the Care and Use of Laboratory Animals and were approved by the Institutional Animal Care and Use Committee of University of Arkansas for Medical Sciences.

Osmotic pumps for PCP or saline (control) infusions were implanted subcutaneous as previously described (Owens et al. 1993). For the time-dependent effect of $\mathrm{PCP}$, rats from treatment groups were infused with PCP at concentration of $18 \mathrm{mg} / \mathrm{kg} /$ day for either 3,10 , or 20 days, whereas saline was infused into the control animals. For the experiments involving effects of various doses of drug, rats were infused with PCP at concentrations of $2.5 \mathrm{mg}, 10 \mathrm{mg}, 18 \mathrm{mg}$, or $25 \mathrm{mg} / \mathrm{kg} /$ day, or saline for 10 days. All pumps were surgically implanted and removed (after the predetermined infusion period) at the same time of day. Animals were sacrificed 24 hours after the last treatment. The brains were removed, and samples were taken from the cerebellum, brainstem, frontal cortex and hippocampus for isolation of the cytosolic fraction.

\section{Preparation of Brain Extracts and Western Blot Analysis}

Cytosolic fractions from the cerebellum, brainstem, frontal cortex, and hippocampus were prepared as pre- viously described (Kyosseva et al. 1999). Briefly, brain tissue was homogenized in $10 \mathrm{mM}$ HEPES buffer, $\mathrm{pH}$ 7.4, containing $1 \mathrm{mM}$ EDTA, $1 \mathrm{mM}$ EGTA, $2 \mathrm{mM}$ sodium orthovanadate, $50 \mathrm{mM}$ NAF, $10 \mathrm{mM}$ sodium pyrophosphate, and $0.5 \%$ NP-40, supplemented with a cocktail of protease inhibitors ( $1 \mathrm{mM}$ PMSF and $5 \mu \mathrm{g}$ / $\mathrm{ml}$ leupeptin, aprotenin, and pepstatin). The homogenate was centrifuged at $12,000 \mathrm{~g}$ for $20 \mathrm{~min}$ at $4^{\circ} \mathrm{C}$. The supernatant was used as the cytosolic fraction in our experiments. The concentration of protein was determined by the method of Bradford (Bradford 1976).

Aliquots of each sample (50 $\mu \mathrm{g}$ of protein) were subjected to 10\% SDS-PAGE and after electrophoresis, the proteins were electrophoretically transferred to nitrocellulose membranes in a buffer containing $25 \mathrm{mM}$ Tris$\mathrm{HCl}, \mathrm{pH} 7.4,190 \mathrm{mM}$ glycine, and 20\% (v/v) methanol. Equal loading and transfer of proteins was confirmed by temporally staining the membranes with Ponceau S solution. The nonspecific binding of proteins was prevented by treating the membranes with $5 \%$ nonfat dry milk in Tris-buffered saline $/ 0.1 \%$ Tween- 20 (TBST), $\mathrm{pH}$ 7.5 for $1 \mathrm{hr}$ at room temperature. The membranes were incubated overnight at $4^{\circ} \mathrm{C}$ with phospho-p44/42 MAP kinase, p44/42 MAP kinase, phospho-MEK 1/2, MEK 1/2, phospho-JNK, JNK, phospho-p38 MAP kinase, or p-38 MAP kinase antibodies, diluted 1:1000 in TBST containing 5\% BSA.

After three washings for $15 \mathrm{~min}$ each, the blotted membranes were incubated with horseradish peroxidase-conjugated anti-rabbit IgG, diluted 1:2000 in TBST containing $5 \%$ milk for $1 \mathrm{hr}$ at room temperature. After further washings, the enhanced chemiluminescence (ECL) method was utilized for detection. The 44- and 42-kD ERK, 54- and 46-kD JNK, and 38-kD p-38 bands were confirmed using control cell extracts (New England Biolabs Inc., Beverly, MA). When necessary, the blots were stripped of detection antibodies by washing the membranes several times with water. The membranes were incubated in a buffer containing $100 \mathrm{mM}$ 2-mercaptoethanol, 2\% SDS, $62.5 \mathrm{mM}$ Tris- $\mathrm{HCl}, \mathrm{pH} 6.7$ at $65^{\circ} \mathrm{C}$ for $30 \mathrm{~min}$. After several washes in TBST, the blots were reprobed with a different antibody using the same procedure.

Densitometric analysis of the blots was performed on a Computerized Laser Densitometer model 300A (Molecular Dynamics, Sunnyvale, CA). The optical density of each band is expressed in arbitrary densitometric units using Image Quant software.

\section{Statistical Analysis}

Results are presented as mean \pm standard deviation (SD) values. Data were analyzed using one-way analysis of variances (ANOVA). When a significant difference was found for the time-dependent experiments, a 
post hoc Bonferroni/Dunnet test was used to determine which PCP dose groups differed from their timematched saline controls. Statistics were conducted using statistical software Statview for Windows, version 4.5 (Abacus Concepts, Inc., Berkeley, CA). A one-way ANOVA followed by a Student-Neuman-Keuls posthoc test was used to compare differences among groups receiving different infusion doses of PCP. This statistical analysis was conducted using the computer software package SigmaStat (Jandel Corporation, San Rafael, CA). P-values less than .05 were considered to be statistically significant.

A
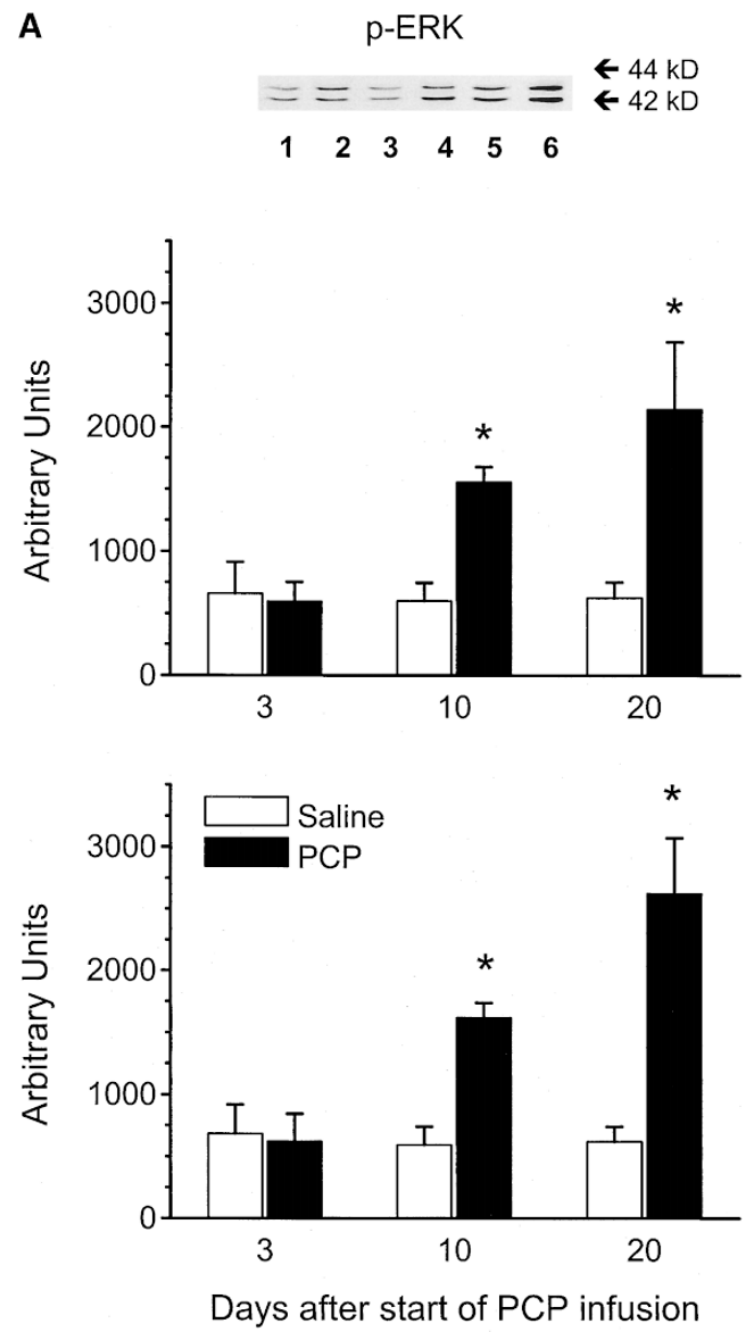

\section{RESULTS}

\section{Time-Dependent Activation of ERK by PCP in Cerebellum}

The first question addressed in this study was whether repeated administration of $\mathrm{PCP}$ could cause activation of ERK1 and ERK2 in the cerebellum. The activation of ERK was determined by Western blot analysis using phospho-specific MAP kinase antibody that detects phosphorylated active forms of ERK1 and ERK2 proteins with 44$\mathrm{kD}$ and 42-kD molecular weights, respectively. Rats were infused for 3, 10 or 20 days with PCP at concentrations of

B
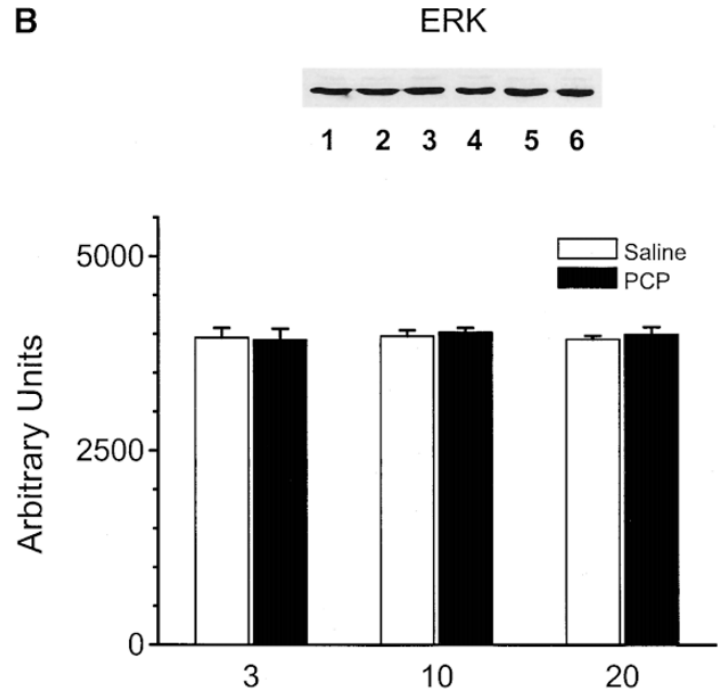

Days after start of PCP infusion

Figure 2. Time-dependent activation of ERK by PCP in rat cerebellum. Rats from the treatment groups were infused with 18 $\mathrm{mg} / \mathrm{kg} /$ day of PCP either for 3, 10, or 20 days. Control rats received saline for 3, 10, or 20 days, respectively. Cytosolic fractions (50 $\mathrm{gg}$ protein/lane) from 3 (lane 1), 10, (lane 2) and 20 days (lane 3) saline or PCP infused rats for 3 (lane 4), 10 (lane 5), and 20 days (lane 6) were subjected to $10 \%$ SDS-PAGE and Western blot analysis using a phospho-specific MAP kinase antibody that detects $44 \mathrm{kD}$ p-ERK1 and $42 \mathrm{kD}$ p-ERK2 (A, upper panel). The enhanced chemiluminescence (ECL) method was used for detection. Data for p-ERK1 (A, middle panel) and p-ERK2 (A, lower panel) were analyzed by scanning densitometry of autoradiograms and are presented as the mean $\pm \mathrm{SD}(n=4$ per group). The immunoblots from Figure $2 \mathrm{~A}$ were reprobed as described in Materials and Methods, and stained with a MAP kinase antibody that detects total ERK levels (B, upper panel). Data for total ERK protein were analyzed by scanning densitometry of autoradiograms and are presented as the mean \pm SD ( $n=4$ per group, B, lower panel). 
$18 \mathrm{mg} / \mathrm{kg} /$ day and control animals were infused with saline for 3, 10 and 20 days. An autoradiogram showing the data for ERK1 and ERK2 from a single rat is presented in Figure 2A (upper panel). Both ERKs have the same pattern of activation after 10 and 20 days of PCP administration. Differences in ERK1 (middle panel) and ERK2 (lower panel) activation were quantified by densitometry and expressed in arbitrary densitometric units. The values for p-ERK1 at three days of PCP infusion were $597 \pm 155$ (SD), at 10 days were $1555 \pm 122$, and at 20 days were $2415 \pm 546$, and for p-ERK2 were $647 \pm$ $170,1618 \pm 121,2623 \pm 450$, respectively.

In the cerebellum of rats, there was no change in the phosphorylated forms of ERK1 and ERK2 at three days, but a statistically significant $(p<.05)$ increase at 10 days (2.5-fold) and 20 days (4-fold) of PCP infusion, as compared to the matched saline controls. When the immunoblots were washed and reprobed using a MAP kinase antibody that recognizes total ERK, no changes in the protein levels of ERK were detected between the two experimental groups for 3, 10, and 20 days (Figure 2B). The anti-MAP kinase antibody used in this experiment mainly detects the 42-kD ERK protein.

\section{Time-Dependent Activation of MEK by PCP in Cerebellum}

The increased phosphorylation of ERK1 and ERK2 in rat cerebellum, following the chronic administration of PCP, could result from activation of upstream intermediates in the ERK pathway. Therefore, we next examined the phosphorylation and expression of MEK, the immediate activator of ERK using Western blot analysis. To determine whether MEK is activated after PCP infusions, immunoblots containing cytosolic samples from the cerebellum of rats treated with PCP for three, 10, or 20 days, as well as from control tissues of rats treated with saline were probed with phospho MEK 1/2 antibody. A representative immunoblot stained with MEK $1 / 2$ antibody, which mainly detects protein with a molecular weight of $46-\mathrm{kD}$ is shown in Figure 3A (upper panel). Differences in the phosphorylated form of MEK were quantified by densitometry of immunoblots from four rats (Figure 3A, lower panel).

The values for $\mathrm{p}$-MEK after three days of PCP infusion were $569 \pm 9$ (SD) arbitrary densitometric units, whereas at 10 days of PCP infusion they were $1099 \pm$ 254 , and at 20 days were $1506 \pm 211$. We found a modest, but not statistically $(p>.1)$ significant increase for phospho-MEK at 10 days and a significant $(p<.05)$ 2-fold increase at 20 days of PCP administration, as compared to the matched saline control animals. The immunoblots were reprobed with a MEK antibody, which detects total levels of MEK protein (Figure 3B). It can be seen that the protein levels were unaffected by chronic PCP infusion in rat cerebellum and were similar for the two experimental groups.
A
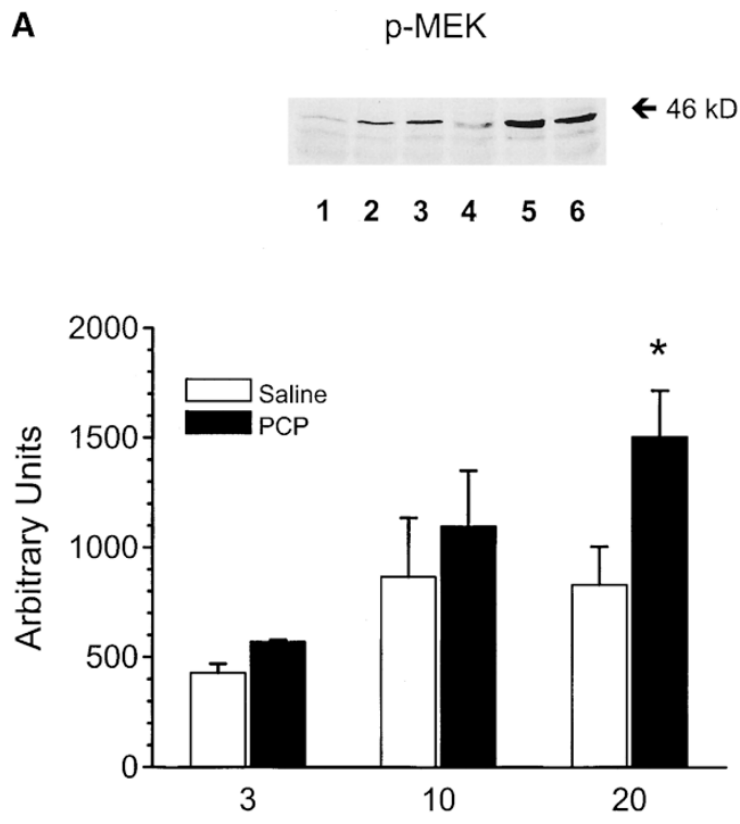

Days after start of PCP infusion

B

MEK

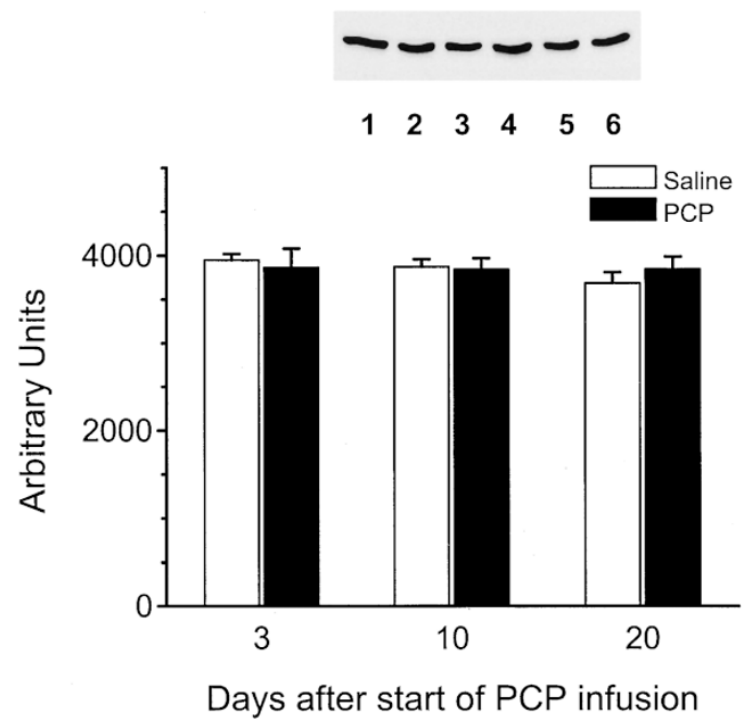

Figure 3. Time-dependent activation of MEK by PCP in rat cerebellum. Cytosolic fractions (50 $\mu \mathrm{g}$ protein/lane) from 3 (lane 1), 10 (lane 2), and 20 days (lane 3) saline or PCPinfused rats for 3 (lane 4), 10 (lane 5), and 20 days (lane 6) were processed for Western blot analysis using a phosphospecific MEK $1 / 2$ antibody (A, upper panel). Data for $\mathrm{p}-\mathrm{MEK}$ were analyzed by scanning densitometry of autoradiograms and are presented as the mean $\pm \operatorname{SD}(n=4$ per group, A, lower panel). The immunoblots from Figure 3A were reprobed using a MEK $1 / 2$ antibody, which detects the protein levels of MEK (B, upper panel). Data for total MEK protein were analyzed by scanning densitometry of autoradiograms and are presented as the mean $\pm \mathrm{SD}(n=4$ per group, $\mathrm{B}$, lower panel). 


\section{A p-ERK}

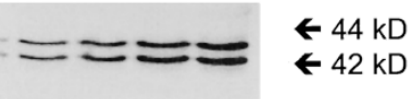

ERK

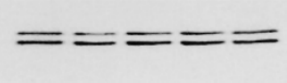

$\begin{array}{lllll}1 & 2 & 3 & 4 & 5\end{array}$
p-JNK

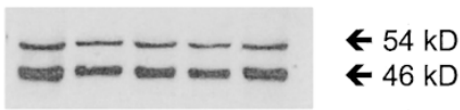

JNK

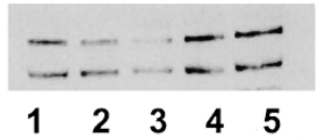

P-ERK1
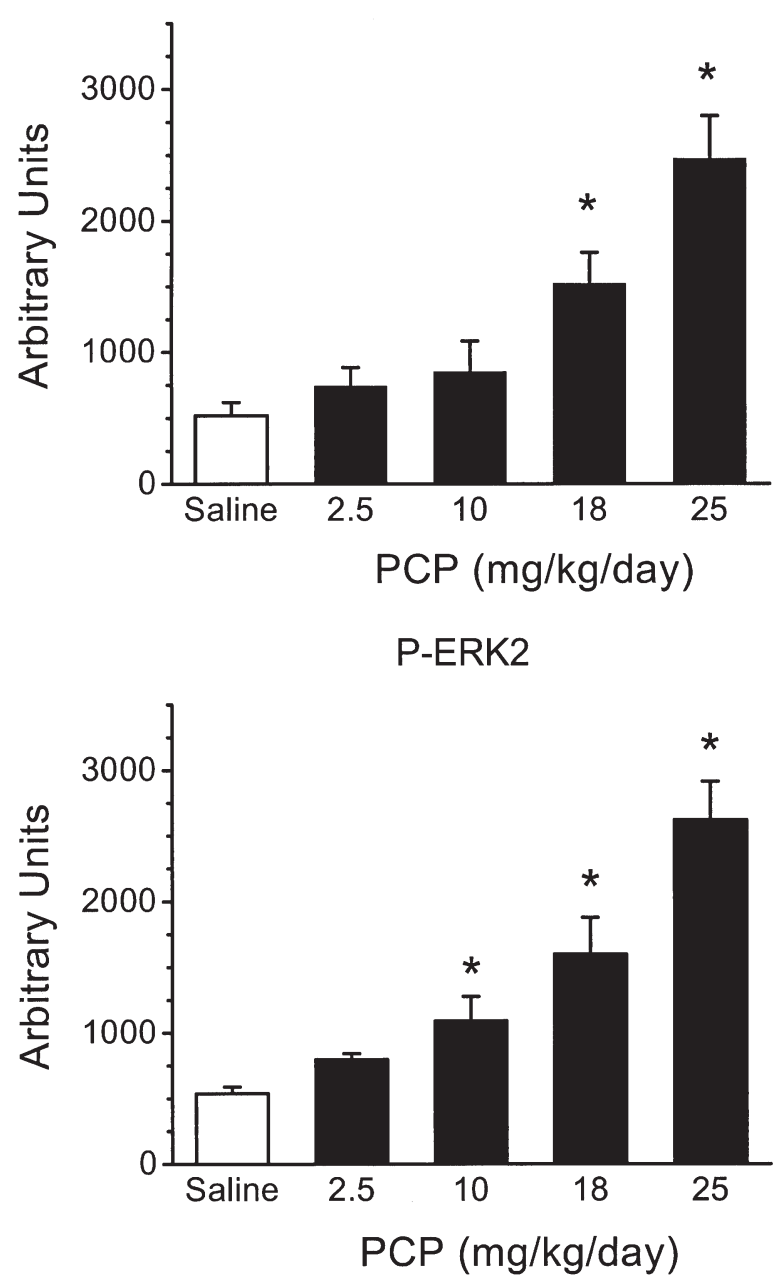

C
P-ERK2 p-p38
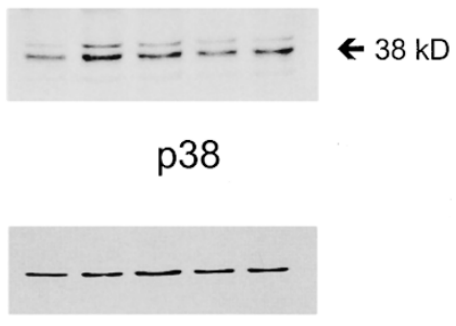

$\begin{array}{lllll}1 & 2 & 3 & 4 & 5\end{array}$ ERK1

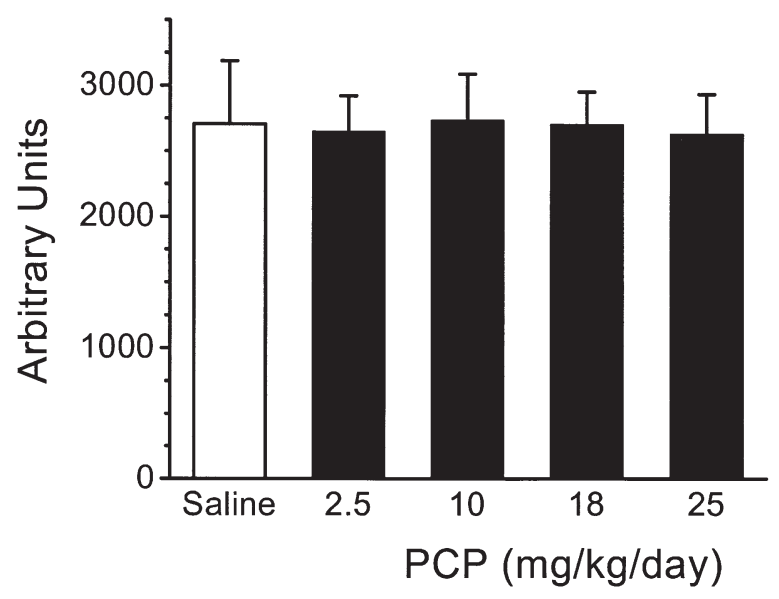

ERK2

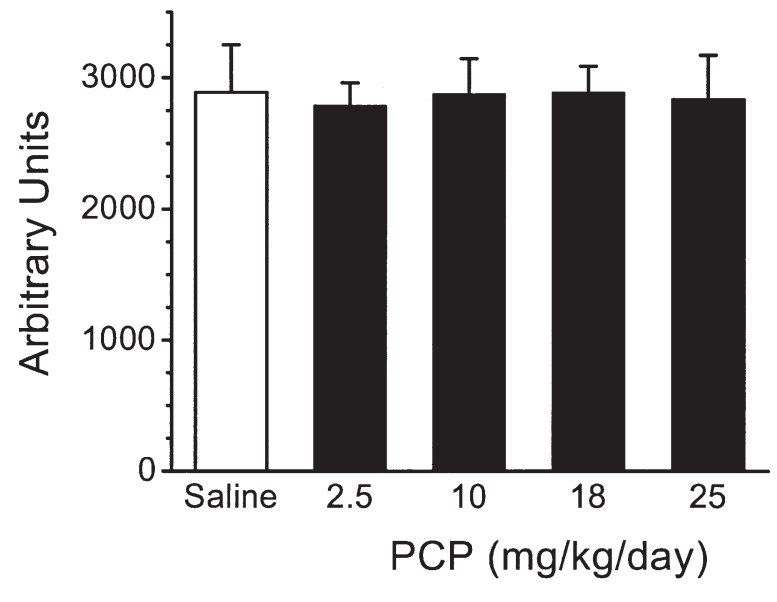

Figure 4. Dose-dependent activation of ERK, JNK, and p38 by PCP in rat cerebellum. Cytosol fractions (50 $\mu \mathrm{g}$ protein/ lane) from saline (lane 1), $2.5 \mathrm{mg}$ (lane 2), $10 \mathrm{mg}$ (lane 3), $18 \mathrm{mg}$ (lane 4), and $25 \mathrm{mg}$ (lane 5) PCP infused rats for 10 days were subjected to $10 \%$ SDS-PAGE, and resulting gels were processed for Western blot analysis using phospho-specific MAP kinase antibodies against p-ERK, p-JNK, and p-p38 (A). The immunoblots were reprobed and stained with ERK, JNK, and p-38 antibodies, which detect the total amount of ERK, JNK, and p38 proteins. Data for p-ERK1 (B, upper panel) and p-ERK2 (B, lower panel), total levels of ERK1 and ERK2 protein (C) in the cerebellum analyzed by scanning of autoradiograms are presented as the mean $\pm \mathrm{SD}(n=4$ per group).

\section{Dose-Dependent Activation of ERK, JNK, and p38 by PCP in Cerebellum}

A second series of experiments assessed the effects of lower and higher doses of PCP on ERK, and two other members of MAP kinase family, JNK and p38 in rat cerebellum. The activation of the three MAP kinases was measured by Western blot analysis using the corresponding phospho-specific antibodies. Rats ( $\mathrm{n}=4$ per group) 
received doses of $2.5,10,18$, and $25 \mathrm{mg} / \mathrm{kg} /$ day of $\mathrm{PCP}$, or saline for 10 days. A representative immunoblot showing the concentration-dependent activation of ERK is presented in Figure 4A. The densitometric analysis revealed a significant increase in phosphorylation of ERK1 (Figure $4 \mathrm{~B}$, upper panel) in PCP-treated rats at concentrations of $18 \mathrm{mg}(1523 \pm 237, p<.05)$ and $25 \mathrm{mg}(2473 \pm 325, p<$ $.05)$ as compared to saline control (520 \pm 99$)$.

The value for $10 \mathrm{mg}$ PCP infusion tended to be significant $(848 \pm 117, p=.54)$. For ERK2 (Figure 4B, lower panel) activation we observed a significant increase of phosphorylation at $10 \mathrm{mg}(1091 \pm 185, p<.05), 18 \mathrm{mg}$ $(1598 \pm 279, p<.05)$, and $25 \mathrm{mg}$ PCP $(2621 \pm 293, p<$ $.05)$ as compared to saline infused rats $(738 \pm 51)$. The total amount of ERK1 (Figure 4C, upper panel) and ERK2 (Figure 4C, lower panel) was not affected by the increasing concentrations of PCP. In contrast to increased ERK activation, we did not observe any elevation in phosphorylation of JNK (54 kD) or JNK (46 kD), and p38 in the cerebellum of rats infused with PCP for up to $25 \mathrm{mg}$ for 10 days (Figure 4A middle panel; densitometric analysis not shown). The total amount of the proteins remained unaltered as well. It should also be noted that high basal levels of phosphorylation for JNK and p38 were detected in the control saline-infused rats.

\section{Dose-Dependent Effect of PCP on ERK, JNK, and p38 in Brainstem, Frontal Cortex and Hippocampus}

Next, we sought to determine if there is a differential and brain region-specific activation of MAP kinases by PCP. We performed Western blot analysis using phosphospecific antibodies against ERK, JNK, and p38 on homogenates of brainstem, frontal cortex and hippocampus (Figure 5). It can be seen from the figure that there was no detectable activation of ERK1 and ERK2, JNK, or p38 in the brainstem, frontal cortex, or hippocampus in rats given PCP in concentrations of $2.5,10,18$, and $25 \mathrm{mg} / \mathrm{kg} /$ day for 10 days as compared to saline infusion. The total amounts of protein of all three members of MAP kinase family were not altered (data not shown). Again, in the three investigated tissues high basal levels of phosphorylation in control rats were observed.

\section{Effect of PCP on ERK in Liver}

Since PCP is metabolized in the liver, we examined the time-dependent activation of ERK1 and ERK2 in liver extracts of animals after chronic administration of PCP $(18 \mathrm{mg} / \mathrm{kg} /$ day). However, Western blot analysis did not reveal any changes in either the phosphorylation or in the total protein levels of ERK from 3, 10, and 20 day PCP-infused rats as compared to control animals (data not shown).

\section{DISCUSSION}

In previous postmortem studies, we demonstrated alterations in the ERK pathway in cerebellar vermis, but not in brainstem or frontal pole (Brodmann area 10), from patients with schizophrenia. We found increased protein levels of ERK2 and decreased protein levels of the corresponding MAP kinase phosphatase (MKP) 2, a dual specificity phosphatase that dephosphorylates both the tyrosine and threonine residues (Kyosseva et al. 1999). We also found an increase in the protein levels of transcription factors Elk-1, CREB and ATF-2 in the cerebellar vermis (Kyosseva et al. 2000).

In addition, the two upstream kinases, MEK and c-Raf were elevated in the vermis as well (unpublished results). Therefore, the present study was designed to determine the role of MAP kinase signal transduction pathways leading to ERK, JNK, and p38 kinase activation following
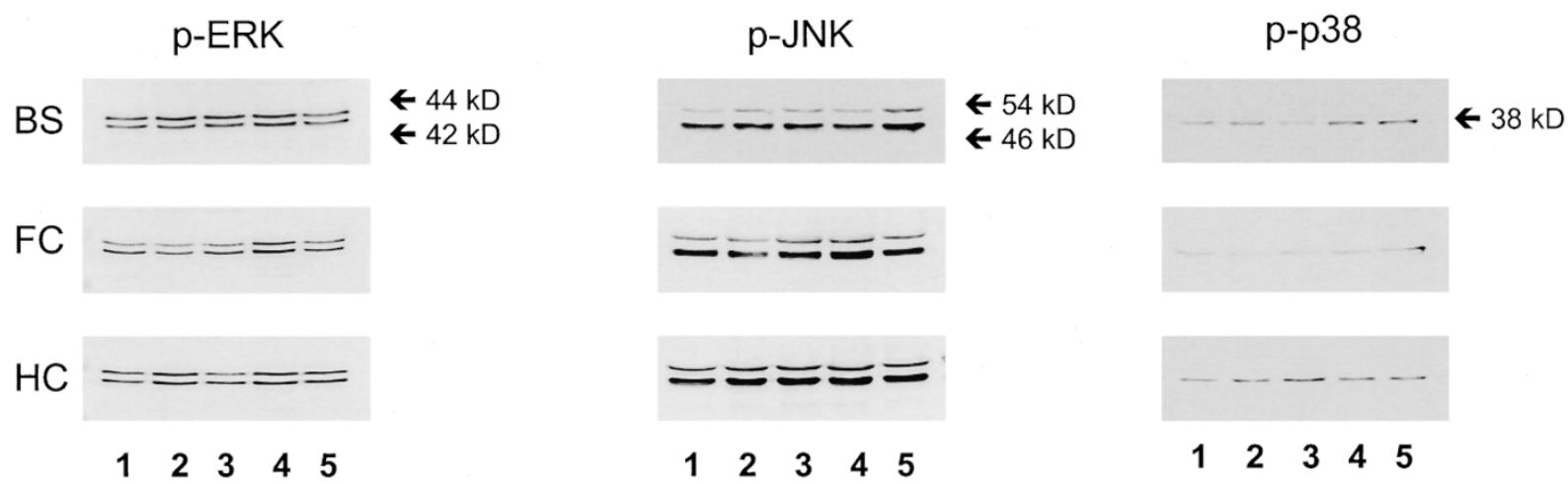

Figure 5. Dose-dependent effect of PCP on ERK, JNK, and p38 in brainstem, frontal cortex, and hippocampus. Cytosol fractions (50 $\mu \mathrm{g}$ protein/lane) from saline (lane 1), $2.5 \mathrm{mg}$ (lane 2), $10 \mathrm{mg}$ (lane 3), $18 \mathrm{mg}$ (lane 4), and $25 \mathrm{mg}$ (lane 5) PCP infused rats for 10 days were subjected to $10 \%$ SDS-PAGE, and resulting gels were processed for Western blot analysis using phospho-specific MAP kinase antibodies against p-ERK, p-JNK, and p-p38. Representative immunoblots $(n=4$ per group) from brainstem (BS), frontal cortex (FC), and hippocampus (HC) are presented. 
chronic administration of the psychotomimetic drug PCP. To assess the activation of ERK, we first examined by Western blot analysis the phosphorylation of ERK1 and ERK2 in the cerebellum of rats treated with PCP for various times. Staining for the dually phosphorylated and active forms of ERK1 and ERK2 reveals a 4-fold increase in the levels of these proteins in the cerebellum of rats given $\mathrm{PCP}$ for 20 days, as compared to saline-infused controls (Figure 2). We have also demonstrated an increase of about 2-fold in the phosphorylation state of MEK in the cerebellum of animals treated with PCP for 20 days (Figure 3). This observation is of some significance because the activation of ERK is the result of sequential activation of this dual specificity kinase (Crews et al. 1992; Zheng and Guan 1993).

In our experiments of time-related activation of ERK, rats were infused with $18 \mathrm{mg} / \mathrm{kg} /$ day PCP. This PCP dose produces a moderate suppression of spontaneous motor activity and other behavioral effects for 3-4 days in male rats (Wessinger and Owens 1991). However, a number of studies have shown induction of stereotyped behaviour, locomotor hyperactivity and ataxia in rats starting from $0.5 \mathrm{mg} / \mathrm{kg}$ PCP (for review, see SamsDodd 1997). Thus, doses of $5-10 \mathrm{mg} / \mathrm{kg}$ PCP were used in rodents to model the schizophrenia state. Therefore, in this study we present data on the effects of PCP doses of $2.5,10,18$, and $25 \mathrm{mg}$, on ERK, JNK, and p38 in several brain regions that are known to be implicated in schizophrenia and PCP psychosis. ERK, JNK, and p38 MAP kinases play important roles in mediating signal transduction from the membrane to the nucleus. Although all three MAP kinases are structurally related, they are activated by different extracellular stimuli (Davis 1994).

Activation of JNK and p38 has been shown to be necessary for the induction of apoptosis in neuronal cells, whereas ERK regulates cell growth and differentiation (Xia et al. 1995). For example, activation and involvement of JNK and p38 MAP kinase in glutamate-induced apoptosis in rat cerebellar granule cells was reported (Kawasaki et al. 1997). However, recent studies demonstrated that neuronal differentiation also can be mediated by p38 MAP kinase in PC12 cells (Morooka and Nishida 1998; Iwasaki et al. 1999) and that ERK1/2 are involved in glutamate-induced apoptotic-like death in cultured rat cortical neurons (Jiang et al. 2000). In this study we found increased dose-dependent phosphorylation of ERK1 and ERK2 in the cerebellum but not in brainstem, frontal cortex and hippocampus. In contrast, no activation of JNK or p38 MAP kinase was observed in all investigated brain regions including cerebellum. It was concluded that three MAP kinases are specifically and differentially activated by chronic administration of PCP in rat brain, suggesting that they may have opposing functions with respect to cell survival and death.

The fact that we have found abnormalities of ERK signal transduction pathway only in the cerebellum of pa- tients with schizophrenia, as well as in rats given $\mathrm{PCP}$, is not surprising because new evidence suggests that the neurocircuitry for schizophrenia may include the cerebellum. Anatomical and neuroimaging studies have shown that the cerebellum is involved in both motor and cognitive function (Allen et al. 1997; Desmond and Fiez 1998; Middleton and Strick 1998; Schmahmann 1998). Several positron emission computed tomography studies have found abnormalities in cerebellar blood flow in a variety of cognitive tasks (Andreasen et al. 1996, 1997). A particular cerebellar region, the anterior vermus was assumed to be important in schizophrenic disorders (Martin and Albers 1995). A recent magnetic resonance imaging study found that patients with schizophrenia had a smaller cerebellar vermis size, accounted by a smaller anterior lobe (Nopoulos et al. 1999). A reduction in the size of the Purkinje cells in the cerebellar vermis of schizophrenic patients has also been reported (Tran et al. 1998).

There is now considerable evidence suggesting a role of MAP kinase cascades in the central nervous system (CNS). A recent study provided evidence for the involvement of MAP kinases in hippocampal long-term potentiation (English and Sweatt 1997). In addition it has been shown that the activation of the MAP kinase pathway is essential in Purkinje cells for the induction of cerebellar long-term depression (Kawasaki et al. 1999).

Despite the increasing numbers of studies suggesting an important role for the MAP kinases in neuronal cells, the role of this signal transduction pathway in various psychiatric disorders and drug-induced psychosis is still poorly understood. It has been shown that electroconvulsive shock (ECS), an effective treatment for depression and schizophrenia, induce activation and tyrosine phosphorylation of ERK1 and ERK2 in rat hippocampus (Kang et al 1994). In a recent report the same group found activation of p38 MAP kinase in both hippocampus and cerebellum and increase of JNK phosphorylation only in rat hippocampus, suggesting a differential activation of MAP kinase family in rat brain following ECS (Oh et al. 1999).

Two studies have examined the effect of chronic morphine and cocaine on ERK and MEK expression in rat brain. Ortiz and coworkers (Ortiz et al. 1995) have reported that chronic morphine treatment selectively increased the levels of ERK1 and ERK2 in locus coeruleus and caudate/putamen. In contrast, they did not find any changes in ERK levels in the other brain regions examined, such as substantia nigra, ventral tegmental area, nucleus accumbens and frontal cortex. On the other hand, chronic, systematic administration of morphine or cocaine is reported to increase the phosphorylation and activity of ERK in ventral tegmental area, thus contributing to a drug-induced increase in tyrosine hydroxylase (Berhow et al. 1996). In that study evidence was also provided that the increase in ERK activity after chronic and morphine treatments is mediated via a glutamate- 
dependent mechanism. Another study suggested that neurotrophin-3 contributes to the initiation of behavioral sensitization to cocaine by activating the Ras/MAP kinase signal transduction cascade (Pierce et al. 1999).

Glutamate, one of the major excitatory neurotransmitters in mammalian CNS, plays an important role in plasticity and toxicity in neurons, and is thought to be involved in various CNS disorders. NMDA-type glutamate receptors modulate multiple signaling pathways, including MAP kinase cascades in neuronal cells (Bading and Greenberg 1991; Xia et al. 1996; Mukherjee et al. 1999). Excitatory neurotransmission through NMDA receptors usually increases intracellular $\mathrm{Ca}^{2+}$ levels. It has been shown that glutamate-induced $\mathrm{Ca}^{2+}$ influx into neurons activates both ERK (Fiore et al 1993b; Kurino et al. 1995; Vanhoutte et al 1999; Schwarzschild et al. 1999) and JNK/SAPK (Schwarzschild et al. 1997) signaling pathways. In contrast, extracellular $\mathrm{Ca}^{2+}$ was not required for the NMDA-receptor-mediated activation of SAPK in cultured striatal neurons (Schwarzschild et al. 1999). PCP acts as a glutamate NMDA receptor antagonist, binding to a specific site located inside the cation channel. It blocks the flow of $\mathrm{Ca}^{2+}$ through the channel and antagonizes the action of NMDA receptor-mediated transmission. Therefore, based on these findings, it may be postulated that the PCP-induction of the ERK signaling pathway in rat cerebellum does not require extracellular $\mathrm{Ca}^{2+}$. However, what is the exact mechanism of ERK activation by PCP is not clear from this study.

In summary, we have shown that chronic administration of PCP in male rats produces a time- and dosedependent activation in the phosphorylated and active forms of several intermediates only of the ERK pathway, specifically in the cerebellum. Our results suggest the possibility that the differential activation of MAP kinases might have important implications for understanding the mechanism of PCP dependence. Furthermore, the fact that we did not detect any differences in the phosphorylated or protein levels of ERK1 and ERK2 in the liver, where this drug is metabolized, suggests a specific alteration of this signal transduction pathway in the brain.

Finally, we believe that PCP infusion into rats can produce a promising model for investigating the molecular mechanism of the ERK signal transduction abnormalities observed in the brains of patients with schizophrenia, as well as in PCP-induced psychosis. Future studies will be necessary to elucidate the mechanism of signal transduction pathways and downstream targets of MAP kinases following chronic and acute administration of PCP.

\section{ACKNOWLEDGMENTS}

This work was supported by grants from the National Institute of Health MH60739 to S.V.K., MH45729 to C.N.K., and
HL-17783 to A.D.E, and a grant from the National Institute on Drug Abuse DA07610 to S.M.O. We thank Melinda Gunnell for her technical assistance.

\section{REFERENCES}

Allen G, Buxton RB, Wong EC, Courchesne E (1997): Attentional activation of the cerebellum of motor involvement. Science 275:1940-1943

Andreasen NC, O'Leary DS, Cizadlo T, Arndt, S Rezai K, Ponto LL, Watkins GL, Hichwa RD (1996): Schizophrenia and cognitive dysmetria: A PET study of dysfunctional and prefrontal-thalamic-cerebellar circuitry. Proc Natl Acad Sci U S A 93: 9985-9990

Andreasen NC, O'Leary DS, Flaum M, Noupolos P, Watkins GL, Ponto LL, Hichwa RD (1997): Hypofrontality in schizophrenia: Distributed dysfunctional circuits in neuroleptic naïve patients. Lancet 349:1730-1734

Bading H, Greenberg ME (1991): Stimulation of protein tyrosine phosphorylation by NMDA receptor activation. Science 253:912-914

Baraban JM, Fiore RS, Sanghera JS, Paddon HB, Pelech SL (1993): Identification of p42 mitogen-activated protein kinases as a tyrosine kinase substrate activated by maximal electroconvulsive shock in hippocampus. J Neurochem 60:330-336

Berhow MT, Hiroi N, Nestler EJ (1996): Regulation of ERK (extracellular signal regulated kinase), part of the neurotrophin signal transduction cascade, in the rat mesolimbic dopamine system by chronic exposure to morphine or cocaine. J Neurosci 16:4707-4715

Berman DE, Hazvi S, Rosenblum K, Seger R, Dudai Y (1998): Specific and differential activation of mitogen-activated protein cascades by unfamiliar taste in the insular cortex of the behaving rat. J Neurochem 18:10037-10044

Bhat RV, Engber TM, Finn JP, Koury EJ, Contreras PC, Miller MS, Dionne CA, Walton KM (1998): Region-specific targets of $\mathrm{p} 42 / \mathrm{p} 44^{\mathrm{MAPK}}$ signaling in rat brain. J Neurochem 70:558-571

Blum S, Moore AN, Adams F, Dash PK (1999): A mitogenactivated protein cascade in the CA1/CA2 subfields of the dorsal hippocampus is essential for long-term spatial memory. J Neurosci 19:3535-3544

Boulton TG, Cobb MH (1991): Identification of multiple extracellular signal-regulated kinases (ERKs) with antipeptide antibodies. Cell Regul 2:357-371

Boulton TG, Nye SH, Robbins DJ, Ip NY, Radziejewska E, Morgenbesser SD, DePinho RA, Panayaotatos N, Cobb MH, Yancopoulos GD (1991): ERKs: A family of protein-serine/threonine kinases that are activated and tyrosine phosphorylated in responses to insulin and NGF. Cell 65:663-675

Bradford MM (1976): A rapid and sensitive method for the quantitation of microgram quantities of protein utilizing the principle of protein-dye binding. Anal Biochem 72:248-254

Campos-Gonzalez R, Kindy MS (1992): Tyrosine phosphorylation of microtubule-associated protein kinase after transient ischemia in the gerbil brain. J Neurochem 59:1955-1958 
Carraway KL, Carraway CA (1995): Signaling, mitogenesis and the cytoskeleton: Where the action is. Bioessays $17: 171-175$

Coyle JT (1996): The glutamatergic dysfunction hypothesis for schizophrenia. Harvard Rev Psychiatry 3:241-253

Crespo P, Xu N, Simonds WF, Gutkind JS (1994): Ras-dependent activation of MAP kinase pathway mediated by G-protein beta gamma subunits. Nature 369:418-420

Crews CM, Alessandrini A, Erikson RL (1992): The primary structure of MEK, a protein kinase that phosphorylates the ERK gene product. Science 258:478-480

Davis RJ (1994): MAPKs: New JNK expands the group. Trends Biochem Sci 19:470-473

Desmond JE, Fiez JA (1998): Neuroimaging studies of the cerebellum language, learning and memory. Trends Cognit Sci 2:355-362

Duman RS (1998): Novel therapeutic approaches beyond the serotonin receptor. Biol Psychiatry 44:324-335

Duman RS, Heninger GR, Nestler EJ (1994): Adaptations of receptor-coupled signal transduction pathways underlying stress- and drug-induced neural plasticity. J Nervous Mental Dis 182:692-700

English JD, Sweatt JD (1997): A requirement for the mitogenactivated protein kinase cascade in hippocampal long term potentiation. J Biol Chem 272:19103-19106

Fiore RS, Bayer VE, Pelech SL, Posada J, Cooper JA, Baraban JM (1993a): p42 mitogen-activated protein kinase in brain: Prominent localization in neuronal cell bodies and dendrites. Neuroscience 55:463-472

Fiore RS, Murphy TH, Sanghera JS, Pelech SL, Baraban JM (1993b): Activation of mitogen-activated protein kinase by glutamate receptor stimulation in rat primary cortical cultures. J Neurochem 61:1626-1633

Flood DG, Finn JP, Walton KM, Dionne CA, Contreras PC, Miller MS, Bhat RV (1998): Immunolocalization of the mitogen-activated protein kinases $\mathrm{p} 42^{\mathrm{MAPK}}$ and JNK1, and their regulatory kinases MEK1 and MEK4, in adult rat central nervous system. J Compar Neurol 398:373-392

Freshney NW, Rawlinson L, Guesdon F, Jones E, Cowley S, Hsuan J, Saklatvala J (1994): Interleukin-1 activates a novel protein kinase cascade that results in the phosphorylation of Hsp27. Cell 78:1039-1049

Gass P, Kiessling M, Bading H (1993): Regionally selective stimulation of mitogen activated protein (MAP) kinase tyrosine phosphorylation after generalized seizures in the rat brain. Neurosci Lett 162:39-42

Guan KL (1994): The mitogen activated protein signal transduction pathway: From the cell surface to the nucleus. Cell Signal 6:581-589

Han J, Lee JD, Bibbs L, Ulevitch RJ (1994): A MAP kinase targeted by endotoxin and hyperosmolarity in mammalian cells. Science 265:808-811

Impey S, Obrietan K, Storm DR (1999): Making new connections: Role of ERK/MAP kinase signaling in neuronal plasticity. Neuron 23:11-14

Iwasaki S, Iguchi M, Watanabe K, Hoshino R, Tsujimoto M, Kohno M (1999): Specific activation of the p38 mitogenactivated protein kinase signaling pathway and induction of neurite outgrowth in PC12 cells by bone morphogenetic protein-12. J Biol Chem 274:26503-26510
Javitt DC (1987): Negative schizophrenic symptomatology and the (PCP) phencyclidine model of schizophrenia. Hill J Clinical Psychiatry 9:12-35

Javitt DC, Zukin SR (1991): Recent advances in the phencyclidine model of schizophrenia. Am J Psychiatry 148:1301-1308

Javitt DC, Balla A, Sershen H, Lajtha A (1999): A.E. Bennett Research Award: Reversal of phencyclidine-induced effects by glycine and glycine transport inhibitors Biol Psychiatry 45:668-679

Jentsch JD, Roth RH (1999): The neuropsychopharmacology of phencyclidine: From NMDA receptor hypofunction to the dopamine hypothesis of schizophrenia. Neuropsychopharmacology 20:201-225

Jiang Q, Gu Z, Zhang G, Jing G (2000): Diphosphorylation and involvement of extracellular signal-regulated kinases (ERK1/2) in glutamate-induced apoptotic-like death in cultured rat cortical neurons. Brain Res 857:71-77

Kang UG, Hong KS, Jung HY, Kim YS, Seong YS, Park JB (1994): Activation and tyrosine phosphorylation of 44kDa mitogen-activated protein kinase (MAPK) induced by electroconvulsive shock in rat hippocampus. J Neurochem 63:1979-1982

Kawasaki H, Morooka T, Shimohama S, Kimura J, Hirano T, Gotoh Y, Nishida E (1997): Activation and involvement of p38 mitogen-activated protein kinase in glutamateinduced apoptosis in rat cerebellar granule cells. J Biol Chem 272:18518-18521

Kawasaki H, Fujii H, Gotoh Y, Morooka T, Shimohama S, Nishida E, Hirano T (1999): Requirement for mitogen activated protein kinase in cerebellar long term depression. J Biol Chem 274:13498-13502

Krystal JH, D'Souza DC, Petrakis IL, Belger A, Berman RM, Charney DS, Abi-Saab W, Madonick S (1999): NMDA agonists and antagonists as probes of glutamatergic dysfunction and pharmacotherapies for neuropsychiatric disorders. Harv Rev Psychiatry 7:125-143

Kurino M, Fukunaga K, Ushio Y, Miyamoto E (1995): Activation of mitogen-activated kinase in cultured rat hippocampal neurons by stimulation of glutamate receptors. J Neurochem 65:1282-1289

Kyosseva SV, Elbein AD, Griffin WS, Mrak RE, Lyon M, Karson CN (1999): Mitogen-activated protein kinases in schizophrenia. Biol Psychiatry 46:689-696

Kyosseva SV, Elbein AD, Hutton TL, Griffin WS, Mrak RE, Sturner WG, Karson CN (2000): Increased levels of transcription factors Elk-1, cyclic adenosine monophosphate response element binding protein, and activating transcription factor-2 in the cerebellar vermis of schizophrenic patients. Arch Gen Psychiatry, 57:685-691

Lewis TS, Shapiro PS, Ahn NG (1998): Signal transduction through MAP kinase cascades. Adv Cancer Res 74:49-139

MacDonald JF, Barlett MC, Mody I, Reynolds JN, Salter MW (1990): The PCP site of the NMDA receptor complex. Adv Exp Med Biol 268:27-34

Marshall CJ (1994): MAP kinase kinase kinase, MAP kinase kinase, and MAP kinase. Cur Opin Genet Dev 4:82-89

Martin P, Albers M (1995): Cerebellum and schizophrenia: A selective review. Schizophr Bull 21:241-250

Middleton FA, Strick P (1998): Cerebellar output: Motor and cognitive channels. Trends Cognit Sci 2:348-354 
Morooka T, Nishida E (1998): Requirement of mitogen-activated protein kinase for neuronal differentiation in PC12 cells. J Biol Chem 273:24285-24288

Mukherjee PK, DeCoster MA, Campbell FZ, Davis RJ, Barzan NG (1999): Glutamate receptor signaling interplay modulates stress-sensitive mitogen-activated protein kinases and neuronal death. J Biol Chem 274:6493-6498

Nopoulos PC, Ceilley JW, Gailis EA, Andreasen NC (1999): An MRI study of cerebellar vermis morphology in patients with schizophrenia: Evidence in support of the cognitive dysmetria concept. Biol Psychiatry 46:703-711

Oh SW, Ahn YM, Kang UG, Kim YS, Park JB (1999): Differential activation of c-Jun N-terminal protein kinase and p38 in rat hippocampus and cerebellum after electroconvulsive shock. Neurosci Lett 271:101-104

Olney JW, Farber NB (1995): Glutamate receptor dysfunction and schizophrenia. Arch Gen Psychiatry 52:998-1007

Ortiz J, Harris HW, Guitart X, Terwilliger RZ, Haycock JW, Nestler EJ (1995): Extracellular signal-regulated protein kinases (ERKs) and ERK kinase (MEK) in brain: Regional distribution and regulation by chronic morphine. J Neurosci 15:1285-1297

Owens SM, Gunnell M, Laurenzana EM, Valentine JL (1993): Dose- and time dependent changes in phencyclidine metabolite covalent binding in rats and the possible role of CYP2D1. J Pharmacol Exp Ther 265:1261-1266

Pierce RC, Pierce-Bancroft AF, Prasad BM (1999): Neurotrophin-3 contributes to the initiation of behavioral sensitization to cocaine by activating the Ras/Mitogenactivated protein kinase signal transduction cascade. J Neurosci 19:8685-8695

Rosette C, Karin M (1996): Ultraviolet light and osmotic stress: Activation of the JNK cascade through multiple growth factor and cytokine receptors. Science 274:1194-1197

Rouse J, Cohen P, Trigon S, Morange M, Alonso-Llamazares A, Zamanillo D, Hunt T, Nebreda AR (1994): A novel kinase cascade triggered by stress and heat shock that stimulates MAPKAP kinasae-2 and phosphorylation of the small heat shock proteins. Cell 78:1027-1037

Sams-Dodd F (1997): Phencyclidine in the social interaction test: An animal model of schizophrenia with face and predictive validity. Rev Neurosci 10:59-90

Sams-Dodd F (1999): Effect of novel antipsychotic drugs on phencyclidine-induced stereotyped behaviour and social isolation in the rat social interaction test. Behav Pharmacol 8;196-215

Schmahmann JD (1998): Dysmetria of thought: Clinical consequences of cerebellar dysfunction on cognition and affect. Trends Cognit Sci 2:362-371

Schwarzschild MA, Cole RL, Hyman SE (1997): Glutamate, but not dopamine, stimulates stress-activated protein kinase and AP-1-mediated transcription in striatal neurons. J Neurosci 17:3455-3466

Schwarzschild MA,Cole RL, Meyers MA, Hyman SE (1999): Contrasting calcium dependencies of SAPK and ERK activations by glutamate in cultured striatal neurons. J Neurochem 72:2248-2255

Thomas KL, Hunt SP (1993): The regional distribution of extracellularly regulated kinase- 1 and 2 messenger RNA in the adult rat central nervous system. Neuroscience 56:741-757

Thornberg SA, Saklad SR (1996): A review of NMDA receptors and the phencyclidine model of schizophrenia. Pharmacotherapy 16:82-93

Tran KD, Smutzer GS, Doty RL, Arnold SE (1998): Reduced Purkinje cell size in the cerebellar vermis of elderly patients with schizophrenia. Am J Psychiatry 155:12881290

Vanhoutte P, Barnier JV, Guibert B, Pages C, Besson MJ, Hipskind RA, Caboche J (1999) Glutamate induces phosphorylation of Elk-1 and CREB, along with c-fos activation, via an extracellular signal-regulated kinasedependent pathway in brain slices. Mol Cell Biol 19:136-146

Wessinger WD, Owens SM (1991): Phencyclidine dependence: The relationship of dose and serum concentrations to operant behavioral effects. J Pharmacol Exp Ther 258:207-215

Xia Z, Dickens M, Raingeaud J, Davis RJ, Greenberg ME (1995): Opposing effects of ERK and JNK-p38 MAP kinases on apoptosis. Science 270:1326-1331

Xia Z, Dudek H, Miranti CK, Greenberg ME (1996): Calcium influx via the NMDA receptor induces immediate early gene transcription by a MAP kinase/ERK-dependent mechanism. J Neurosci 16:5425-5436

Zheng CF, Guan KL (1993): Cloning and characterization of two distinct human extracellular signal-regulated kinase activator kinases, MEK 1 and MEK 2. J Biol Chem 268:11435-11439 